\title{
ANALISIS TINGKAT AKURASI ALGORITMA NOVEL SEBAGAI METODE PREDIKSI (STUDI KASUS :PREDIKSI HARGA EMAS)
}

\author{
Hafiz Riyadli ${ }^{1}$, Arliyana ${ }^{2}$ \\ Program Studi Sistem Informasi ${ }^{1}$, Program Studi Manajemen Informatika ${ }^{2}$ \\ Sekolah Tinggi Manajemen Informatika dan Komputer (STMIK) Palangkaraya \\ Jalan George Obos Nomor 114, Palangka Raya, Kalimantan Tengah \\ Email : hafiz.riyadli@gmail.com¹, arliyana.85@gmail.com²
}

\begin{abstract}
Fuzzy method in the world of information and communication technology especially in the domain of intelligent systems, which one can be used to predictions/ forecasting. In this study the author will use the Novel Algorithm presented by Jasim, Salim and Ibraheem as a method to predictioning the Gold Price, the data source is retrieved from the http://www.kitco.com. Then the predictions result with Novel Algorithm will be comparing with fuzzy time series methods presented by Ruey Chyn Tsaur. Results of the predictions using Novel Algorithm, obtained a value of MAPE $\mathbf{0 , 0 3 8 5}(3,85 \%)$, while the Fuzzy Time Series Ruey Chyn Tsaur, obtained results of MAPE $\mathbf{0 , 0 5 4 4}(5,44 \%)$.
\end{abstract}

Keywords : Predictions, Fuzzy Time Series, Novel Algorithms, Ruey Chyn Tsaur, MAPE

\section{PENDAHULUAN}

Pada saat sekarang ini, perkembangan dunia teknologi informasi dan komunikasi terus bergerak sangat cepat dan pesat sekali, baik perkembangan teknologi perangkat keras, perangkat lunak, hingga perkembangan dalam metode komputasi juga dapat dirasakan sangat pesat.Salah satu metode komputasi yang juga berkembang sangat pesat adalah sistem cerdas.Sistem cerdas dalam dunia teknologi informasi dan komunikasi salah satunya dapat digunakan untuk melakukan peramalan, dimana salah satu metode yang sering digunakan dalam ranah sistem cerdas ini adalah metode $f u z z y /$ logika fuzzy.

Logika Fuzzy diperkenalkan pertama kali oleh Prof. Lutfi Zadeh, seorang guru besar pada University of California Berkeley berkebangsaan Iran pada sekitar tahun 1965. Beberapa penelitian telah dilakukan untuk memecahkan permasalahan peramalan menggunakan data time series yang diperkenalkan 
pertama kali oleh Song dan Chissom (1993). Dalam penelitian ini penulis akan menggunakan Algoritma Novel yang dikemukakan oleh Jasim, Salim dan Ibraheem (2012) untuk memprediksi Harga Emas dan juga membandingkan hasilnya menggunakan fuzzy time series yang dikemukakan oleh Ruey Chyn Tsaur (2012) sebagai metode pembanding.

Sumber data yang diperlukan adalah data Harga Emas (Emas Batangan) yang diperoleh dari http://www.kitco.com.

Berdasarkan uraian diatas, maka dapat dirumuskan permasalahan yaitu Bagaimana tingkat keakuratan hasil prediksi harga Emas Menggunakan Algoritma Novel

Batasan masalah yang dijadikan dasar dalam analisis ini adalah sebagai berikut :

1. Metode prediksi yang digunakan adalah Algoritma Novel Berbasis Fuzzy Time Series yang dikemukakan oleh Jasim, Salim dan Ibraheem, kemudian hasilnya akan dibandingkan dengan metode Fuzzy Time Series - Rantai Markov yang dikemukakan oleh Rhuey Chyn Tsaur.

2. Data yang digunakan dalam penelitian ini adalah data tahunan yang diperoleh dari http://www.kitco.com selama 16 (enam belas) tahun, yakni mulai dari data tahun 2000 sampai dengan data tahun 2015. Harga Emas yang digunakan dalam satuan US Dollar per Oz.

3. Metode pengujian tingkat kesalahan peramalan menggunakan metode Mean Absolute Percentage Error (MAPE)

Berdasarkan permasalahan yang telah uraian diatas, maka tujuan penelitian ini adalah sebagai berikut :

1. Untuk menganalisis tingkat keakuratan hasil prediksi menggunakan Algoritma Novel Berbasis Fuzzy Time Seriesyang dikemukakan oleh Jasim, Salim dan Ibraheem terhadap prediksi harga emas.

2. Memberikan tambahan literatur keilmuan bagi STMIK Palangkaraya khususnya untuk ranah logika samar dan prediksi.

Sedangkan manfaat yang ingin diperoleh dengan adanya penelitian ini adalah agar dapat digunakan sebagai bahan pertimbangan pada studi kasus peramalan yang akan dilakukan oleh penulis berikutnya. 
Penelitian tentang prediksi/ peramalan ini hanya membahas tingkat akurasi algoritma novel terhadap prediksi harga emas, yang datanya di ambil dari laman http://www.kitco.com yang merupakan salah satu situs yang menyajikan informasi dan data historis dari pergerakan harga emas dunia dalam satuan US Dollar per Oz. Data harga emas yang digunakan oleh penulis adalah data harga emas tahunan selama 16 tahun, mulai dari tahun 2000 sampai dengan tahun 2015.

\section{TINJAUAN PUSTAKA}

Penelitian tentang peramalan/ prediksi pernah dilakukan oleh Rhuey Chyn Tsaur (2012) dengan judul $A$ Fuzzy Time Series-Markov Chain Model With an Application to Forecast the Exchange Rate Between the Taiwan an US Dollar. Sebelum melakukan permalan terhadap nilai tukar mata uang dolar taiwan dengan dolar amerika serikat, Rhuey Chyn Tsaur lebih dulu melakukan perbandingan perhitungan dengan lima penelitian sebelumnya dengan menggunakan data yang sama yaitu data penerimaan mahasiswa di Universitas Alabama dari tahun 1971 sampai dengan 1992, dan hasil perhitungan Rhuey Chyn Tsaur ini menghasilkan nilai MAPE kecil dengan hasil $1,4042 \%$.

Penelitian selanjutnya mengangkat topic tentang Prediksi Indeks Harga Saham Gabungan (IHSG) Dengan Fuzzy Time Series Using Precentage Change yang dilakukan oleh Puspitasari, dkk (2012) merupakan penelitian yang melakukan peramalan model data dan nilai data untuk waktu $\mathrm{t}+1$ berdasarkan presentase perubahan data IHSG mulai dari tanggal 1 Mei sampai dengan 27 September 2012 yang akan dibandingkan hasilnya dengan simulasi yang menggunakan 100 data yang dibangkitkan secara acak.

Penelitian ketiga dilakukan oleh Apriliyah, dkk (2008) mengenai Perkiraan Penjualan Beban Listrik Menggunakan Jaringan Syaraf Tiruan Resilent Back Propagation (RPROP). Data yang digunakan meliputi data pelanggan, biaya beban, biaya pemakaian, dan biaya kelebihan pemakaian beban. Dari hasil perhitungan didapatkan rata-rata error sebesar $0,756 \%$.

Penelitian selanjutnya dilakukan oleh Berutu (2013) untuk meramalkan penjualan mobil nasional menggunakan metode fuzzy time series Ruey Chyn Tsaur. Menggunakan data penjualan 15 
jenis mobil nasional, dan hasil peramalan diukur keakuratannya menggunakan metode MSE.

\section{KAJIAN TEORI}

\section{Prediksi/ Peramalan}

Prediksi/Peramalan dapat diartikan sebagai kegiatan memperkirakan, memprediksi, serta menghitung probabilitas kemungkinan kejadian yang akan terjadi dimasa yang akan datang, dengan didasarkan pada faktafakta berkaitan atau data historis yang telah terjadi di masa lalu.

\section{Logika Fuzzy}

Logika fuzzy atau juga bisa juga disebut sebagai Logika Samar, yang sebenarnya mempunyai arti logika yang digunakan untuk menggambarkan ketidakjelasan. Logika Fuzzy merupakan salah satu logika pembentuk dalam dunia soft computing. Logika fuzzy pertama kali diperkenalkan oleh Prof. Lotfi Asker Zadeh pada tahun 1965, seorang Professor dari Universitas California Berkeley kelahiran Iran.

\section{a. Definisi Logika Fuzzy}

Logika fuzzy adalah suatu cara yang tepat untuk memetakan suatu ruang input ke dalam suatu ruang output, mempunyai nilai kontiniu dan logika fuzzy dinyatakan dalam derajat dari suatu keanggotaan dan derajat dari kebenaran (Kusumadewi, 2003:153)

b. Fuzzy Time Series

Teori himpunan fuzzy Zadeh digunakan untuk mengembangkan model time variant dan time invariant peramalan fuzzy time series dengan menerapkan pada masalah peramalan pendaftaran mahasiswa baru dengan data berkala pada Alabama University (Song dan Chissom, 1993).

Beberapa penelitian dan pengembangan metode ini yaitu peramalan dengan metode fuzzy time series pada pendaftaran mahasiswa baru Universitas Alabama menggunakan operasi aritmetika sederhana (Chen, 2002), Model second order fuzzy time series untuk meramal pendaftaran mahasiswa di Alabama University (Tsai dan $\mathrm{Wu}, 1999)$, Menggunakan model high order fuzzy time series untuk mengatasi kelemahan model first order fuzzy time series dengan mengimplementasikan pada peramalan pendaftaran mahasiswa pada Alabama University (Chen, 2002), Model 2 faktor high-order fuzzy logical relationship untuk meningkatkan akurasi peramalan (Lee dkk, 2006) selanjutnya metode high order fuzzy 
time series untuk memprediksi temperatur dan peramalan TAIFEX (Lee dkk, 2006).

c. Algoritma Novel Berbasis Fuzzy Time Series

Langkah-langkah peramalan dengan Algoritma Novel berbasis Fuzzy Time Series yang dikemukakan oleh Haneen Talal Jasim,Abdul Ghafoor Jasim Salim, dan Kais Ismail Ibraheem tahun 2012 adalah sebagai berikut (Jasim dkk., 2012)

Langkah 1. Mengumpulkan data

Langkah 2. Menentukan nilai maksimum dan nilai minimum dari interval $\left[\mathrm{D}_{\min }-\mathrm{D}_{1}, \mathrm{D}_{\max }+\mathrm{D}_{2}\right]$, dimana $\mathrm{D}_{1}$ dan $\mathrm{D}_{2}$ merupakan nilai konstanta untuk menentukan Universe of discourse $U$.

\section{Langkah 3.}

a: Penentuan Interval I menggunakan metode average based length (Duru dan Yoshida, 2009) sebagai berikut :

$$
a v=\frac{\sum_{i=1}^{n}\left(\mathrm{D}_{\mathrm{i}}-\mathrm{D}_{\mathrm{i}-1}\right)}{n-1}
$$

dimana $\mathrm{n}$ adalah banyaknya data.

b: kemudian hitung nilai tengah menggunakan rumus $(\mathrm{B}=\mathrm{av} / 2)$

c: Tentukan range dari hasil $\mathrm{B}$ berdasarkan Tabel 1 :
Tabel 1. Base Mapping

\begin{tabular}{|c|c|}
\hline Range & Base \\
\hline $0.1-1$ & 0.1 \\
\hline $1-10$ & 1 \\
\hline $10-100$ & 10 \\
\hline $100-1000$ & 100 \\
\hline $1000-10000$ & 1000 \\
\hline
\end{tabular}

Langkah 4. Menetukan nilai dari interval fuzzy menggunakan rumus sebagai berikut : $m=(\operatorname{Dmax}+D 1-$ Dmin-D2)/I

Langkah 5. Menentukan himpunan Fuzzy logical sebagai berikut $: A i=\left(d_{i-1}\right.$, $\left.\mathrm{d}_{\mathrm{i}}, \mathrm{d}_{\mathrm{i}+1}, \mathrm{~d}_{\mathrm{i}+2}\right)$ dimulai dari $\mathrm{A} 1=\left(\mathrm{d}_{0}, \mathrm{~d}_{1}\right.$, $\left.\mathrm{d}_{2}, \mathrm{~d}_{3}\right)$ dan berakhir pada $\mathrm{A}_{\mathrm{m}}=\left(\mathrm{d}_{\mathrm{m}-1}, \mathrm{~d}_{\mathrm{m}}\right.$, $\left.\mathrm{d}_{\mathrm{m}+1}, \mathrm{~d}_{\mathrm{m}+2}\right)$, dimana $\mathrm{d}_{0}=$ Dmin $-\mathrm{Id}_{\mathrm{m}+2}=$ Dmax dan fuzzifikasi data historis menandakan nilai linguistik data diwakili oleh satu set himpunan fuzzy 1 $\leq I \leq \mathrm{m}$.

Langkah 6. Menentukan Fuzzy Logical Relations sebagai berikut : $\mathrm{Aj} \rightarrow \mathrm{Ai}$

Langkah 7. Cari Fuzzy Logical Group

Langkah 8. Hitung hasil peramalan. Nilai peramalan pada waktu $t$ ditentukan berdasarkan ketentuan berikut :

A : jika Fuzzy Logical Relationship Group (FLRG) $\mathrm{A}_{\mathrm{j}}$ adalah kosong $\mathrm{A}_{\mathrm{j}} \rightarrow \emptyset$, maka nilai $\mathrm{F}_{\mathrm{vt}}$ adalah nilai tengah dari interval $\mathrm{Aj}$ dimana

$$
A_{j}=\left(d_{j-1}, d_{j}, d_{j+1}, d_{j+2}\right)
$$


B : jika FLRG $\mathrm{A}_{\mathrm{j}}$ adalah relasi one to one $\mathrm{A}_{\mathrm{j}} \rightarrow \mathrm{A}_{\mathrm{k}}$ maka interval yang mengandung nilai peramalan adalah $\mathrm{A}_{\mathrm{k}}$ dan selanjutnya menggunakan ketentuan untuk memperoleh peramalan

(1) Jika j > i, dan $Y>0$, maka kecenderungan peramalan akan menaik dan menggunakan aturan 2 untuk meramalkan data tersebut.

(2) Jika j > i, dan $\mathrm{Y}<0$, maka kecenderungan peramalan akan menurun dan menggunakan aturan 3 untuk meramalkan data tersebut.

(3) Jika j $<$ i, dan $Y>0$, maka kecenderungan peramalan akan menaik dan menggunakan aturan 2 untuk meramalkan data tersebut.

(4) Jika j $<$ i, dan $\mathrm{Y}<0$, maka kecenderungan peramalan akan menurun dan menggunakan aturan 3 untuk meramalkan data tersebut.

(5) Jika j = i, dan $Y>0$, maka kecenderungan peramalan akan menaik dan menggunakan aturan 2 untuk meramalkan data tersebut.

(6) Jika j = i, dan $\mathrm{Y}<0$, maka kecenderungan peramalan akan menurun dan menggunakan aturan 3 untuk meramalkan data tersebut.

Aturan 1, 2 dan 3 adalah sebagai berikut:
Aturan 1. Jika Nilai data (n-1) dikurang data $(\mathrm{n}-2)$ । $/ 2>\mathrm{A}_{\mathrm{j}} / 2$, maka kecenderungan peramalan pada interval ini menaik dan $F_{n}=0.75$ dari $A_{j}$. Jika Nilai data (n-1) dikurang data (n-2) I $/ 2=\mathrm{A}_{\mathrm{j}} / 2$, maka peramalan adalah nilai tengah interval.

Jika Nilai data (n-1) dikurang data (n-2) I $/ 2<\mathrm{A}_{\mathrm{j}} / 2$, maka kecenderungan peramalan pada interval ini menurun dan $\mathrm{F}_{\mathrm{n}}=0.25$ dari $\mathrm{A}_{\mathrm{j}}$.

Aturan 2. Jika $\mathrm{x}=|\mathrm{Y}| * 2+$ data $(\mathrm{n}-1) \epsilon$ $\mathrm{A}_{\mathrm{j}}$ atau $\mathrm{x}=$ data $(\mathrm{n}-1)-|\mathrm{Y}| * 2 \epsilon \mathrm{A}_{\mathrm{j}}$, maka kecenderungan peramalan pada interval ini menaik dan $F_{n}=0.75$ dari $A_{j}$.

Jika $\mathrm{x}=\frac{|\mathrm{Y}|}{2}+$ data $(\mathrm{n}-1) \in \mathrm{A}_{\mathrm{j}}$ atau $\mathrm{x}=$ data (n-1) - $\frac{|\mathrm{Y}|}{2} \epsilon \mathrm{A}_{\mathrm{j}}$, maka kecenderungan peramalan menurun dan $F_{n}=0.25$ dari $A_{j}$.

Jika bukan keduanya, maka hasil peramalan adalah nilai tengah dari interval $A_{j}$.

Aturan 3. Jika $x=\frac{|Y|}{2}+$ data $(n-1) \epsilon$ $\mathrm{A}_{\mathrm{j}}$ atau $\mathrm{x}=$ data $(\mathrm{n}-1)-\frac{|\mathrm{Y}|}{2} \epsilon \mathrm{A}_{\mathrm{j}}$, maka kecenderungan peramalan pada interval ini menurun dan $\mathrm{F}_{\mathrm{n}}=0.25$ dari $\mathrm{A}_{\mathrm{j}}$. Jika $\mathrm{x}=|\mathrm{Y}| * 2+$ data $(\mathrm{n}-1) \in \mathrm{A}_{\mathrm{j}}$ atau $\mathrm{x}$ $=$ data $(\mathrm{n}-1)-|\mathrm{Y}| * 2 € \quad \mathrm{~A}_{\mathrm{j}}$, maka kecenderungan peramalan pada interval ini menaik dan $F_{n}=0.75$ dari $A_{j}$. 
Jika bukan keduanya, maka hasil peramalan adalah nilai tengah dari interval $A_{j}$. (Chen, 2002)

C : jika FLRG $\mathrm{A}_{\mathrm{j}}$ adalah relasi one to many $\mathrm{A}_{\mathrm{j}} \rightarrow \mathrm{A}_{\mathrm{k} 1}, \mathrm{~A}_{\mathrm{k} 2}, \ldots, \mathrm{A}_{\mathrm{kp}}$, maka peramalan mengikuti ketentuan sebagai berikut :

(1) jika perbedaan antara dua $\mathrm{k} 1$, $\mathrm{k} 2, \ldots, \mathrm{kp} \leq 2$ maka nilai interval peramalannya adalah :

$$
\begin{aligned}
I F_{\mathrm{vt}}= & \frac{\mathrm{A}_{\mathrm{k} 1}+\mathrm{A}_{\mathrm{k} 2}+\ldots .+}{\mathrm{P}} \\
= & \frac{\left(\mathrm{d}_{\mathrm{k} 1-1}+\mathrm{d}_{\mathrm{k} 2-1}+\ldots+\mathrm{d}_{\mathrm{kp}-}\right.}{\mathrm{P}} \\
& \frac{\mathrm{d}_{\mathrm{k} 1}+\mathrm{d}_{\mathrm{k} 2}+\ldots+\mathrm{d}_{\mathrm{kp}},}{\mathrm{P}} \\
& \frac{\mathrm{d}_{\mathrm{k} 1+1}+\mathrm{d}_{\mathrm{k} 2+1}+\ldots \mathrm{d}_{\mathrm{kp}+1}}{\mathrm{~d} \mathrm{~d}_{\mathrm{k} 1+2}+\mathrm{d}_{\mathrm{k} 2+2}+\ldots+}
\end{aligned}
$$

Maka hasil peramalannya adalah nilai tengah interval tersebut.

(2) jika perbedaan antara dua k1, $\mathrm{k} 2, \ldots, \mathrm{kp}>2$ maka nilai interval peramalannya adalah :

$$
\begin{aligned}
& \mathrm{IF}_{\mathrm{vt}}=\frac{\mathrm{A}_{\mathrm{k} 1}+\mathrm{A}_{\mathrm{k} 2}+\ldots .+\mathrm{A}_{\mathrm{ki}-1}+\mathrm{A}_{\mathrm{i}+1}+\ldots+}{\mathrm{P}} \\
& =\frac{\left(\mathrm{d}_{\mathrm{k} 1-1}+\ldots+\mathrm{d}_{(\mathrm{ki}-1)-1}+\mathrm{d}_{(\mathrm{ki}+1)-1+\ldots+}\right.}{\mathrm{d}_{\mathrm{kp}-1},} \\
& \mathrm{~d}_{\mathrm{k} 1}+\ldots+\mathrm{d}_{(\mathrm{ki}-1)}+\mathrm{d}_{(\mathrm{ki}+1)}+\ldots+
\end{aligned}
$$

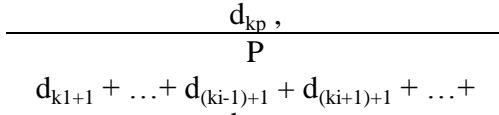

$$
\begin{aligned}
& \frac{\mathrm{d}_{\mathrm{k} 1+1}+\ldots+\mathrm{d}_{(\mathrm{ki}-1)+1}+\mathrm{d}_{(\mathrm{ki}+1)+1}+\ldots+}{\mathrm{d}_{\mathrm{kp}+1},} \\
& \frac{\mathrm{d}_{\mathrm{kp}+2}}{\mathrm{P}}
\end{aligned}
$$

Dimana $A_{k i}$ adalah interval yang mempunyai perbedaan $>2, \mathrm{I}=1,2, \ldots, p$ dan peramalan himpunan fuzzy $\mathrm{A}_{\mathrm{ki}}$ adalah perhitungan one to onefuzzy logical relationship dengan mengaplikasikan Langkah 8.

\section{Metode Evaluasi}

Metode evaluasi yang digunakan adalah metode Mean Absolute Percentage Error (MAPE). Metode MAPE adalah metode yang digunakan untuk mengevaluasi prediksi/ peramalan (Tsaur, 2012). Rumus metode MAPE adalah sebagai berikut :

$$
M A P E=\frac{1}{n} \sum_{t=1}^{n}\left(\frac{\left(Y_{t}-Y^{\prime}{ }_{t}\right)}{Y_{t}}\right)
$$

Dimana :

$$
\begin{aligned}
\text { MAPE }= & \text { mean absolute percentage } \\
& \text { error } \\
\mathrm{Y}_{\mathrm{t}}= & \text { data aktual kurs Rupiah } \\
\mathrm{Y}^{\prime}{ }_{\mathrm{t}}= & \text { data hasil peramalan } \\
\mathrm{N} & =\text { jumlah data } \\
\mathrm{t} & =\text { tahun }
\end{aligned}
$$

\section{Pendekatan Penelitian}

Penelitian ini merupakan penelitian komparatif, yaitu suatu penelitian yang bersifat membandingkan. Variabelnya masih sama dengan penelitian varabel mandiri tetapi untuk sampel yang lebih dari satu, atau dalam waktu yang berbeda. 


\section{Teknik Pengumpulan Data}

Teknik pengumpulan data yang penulis gunakan dalam penelitian ini adalah sebagai berikut :

a. Kepustakaan

Dalam hal ini, penulis mengumpulkan dan mempelajari sejumlah buku, artikel, jurnal, serta referensi yang berhubungan dengan judul yang penulis bahas.

b. Dokumentasi

Penulis memperolehdan mempelajari data-data mengenai harga emas melalui situs-situs jual beli emas resmi yang ada, terutama dari sumber http://www.kitco.com sebagai sumber utama.

\section{Metode Analisis}

Tahapan penelitian yang penulis gunakan dalam penelitian ini adalah sebagai berikut :

a. Pengumpulan data dan Pengamatan data yang diperoleh.

b. Menentukan universe of discourse (semesta pembicaraan) berdasarkan data yang diperoleh.

c. Menghitung dan menentukan interval aktif dari semesta pembicaraan.

d. Menentukan Fuzzy Logical, Fuzzy Logical Relasionship, serta Fuzzy Logikal Relationship Group. e. Menghitung nilai peramalan berdasarkan kaidah-kaidah aturan dan ketentuan masing-masing metode yang digunakan.

f. Melakukan evaluasi hasil peramalan akhir yang diperoleh dari dua metode tersebut menggunakan metode MAPE.

\section{PEMBAHASAN}

\section{Bahan Penelitian}

Dalam melakukan penelitian ini, bahan penelitian yang dibutuhkan penulis yaitu dataharga emas dunia yang diperoleh dari http://www.kitco.com.

Dalam penelitian ini, penulis mengambil data harga emas yang merupakan data tahunan, yang dimulai dari tahun 2000 sampai dengan tahun 2015, dalam satuan USD per Oz, yang dapat dilihat pada Tabel 2 :

Tabel 2. Harga Emas

\begin{tabular}{|c|r|}
\hline Tahun & US Dollar / Oz \\
\hline 2000 & 279,11 \\
\hline 2001 & 271,04 \\
\hline 2002 & 309,73 \\
\hline 2003 & 363,38 \\
\hline 2004 & 409,72 \\
\hline 2005 & 444,74 \\
\hline 2006 & 603,46 \\
\hline 2007 & 695,39 \\
\hline 2008 & 871,96 \\
\hline 2009 & 972,35 \\
\hline 2010 & 1224,53 \\
\hline
\end{tabular}




\begin{tabular}{|c|r|}
\hline Tahun & US Dollar $/ \mathbf{~ O z}$ \\
\hline 2011 & 1571,52 \\
\hline 2012 & 1668,98 \\
\hline 2013 & 1411,23 \\
\hline 2014 & 1266,4 \\
\hline 2015 & 1160,06 \\
\hline
\end{tabular}

Sumber :http://www.kitco.com

\section{Hasil Analisis}

Berdasarkan data harga emas pada Tabel 2, selanjutnya adalah memasukkan nilai-nilai tersebut kedalam langkah-langkah penyelesaian menggunakan Algoritma Novel yang dikemukakan oleh Jasim, Salim dan Ibraheem yang telah dikemukakan sebelumnya.

\section{Penyelesaian Algoritma Novel}

Langkah - langkah prediksi menggunakan Algoritma Novel yang dikemukakan oleh Jasim, Salim dan Ibraheem (2012) ialah sebagai berikut :

Langkah 1. Mengumpulkan data

Langkah 2. Penentuan nilai minimal dan maksimal dapat didefinisikan sebagaiberikut :

$$
\begin{array}{ll}
\mathbf{D}_{\min } & =271,04 \\
\mathbf{D}_{\max } & =1668,98 \\
\mathbf{D}_{1} & =71,04 \\
\mathbf{D}_{\mathbf{2}} & =31,02 \\
\mathbf{U} & =[271,04-71,04 ; \\
& \\
& =[2068,98+31,02] \\
&
\end{array}
$$

Langkah 3, 4 dan 5.

Berdasarkan ketentuan dan rumus perhitungan yang terdapat pada langkah 3, maka didapat nilai $\mathrm{B}=$ 127,66 dimana berdasarkan tabel base mapping(tabel 1) maka $I=100$. Selanjutnya berdasarkan rumus pada langkah 4, dari $\mathbf{U}=[200,1700]$ maka didapat banyaknya $\mathrm{m}=15$, sehingga didapat himpunan fuzzy sebagai berikut:

$$
\begin{array}{ll}
\mathrm{A}_{1} & =[200,300] ; \\
\mathrm{A}_{2} & =[300,400] ; \\
\mathrm{A}_{3} & =[400,500] ; \\
\mathrm{A}_{4} & =[500,600] ; \\
\mathrm{A}_{5} & =[600,700] ; \\
\mathrm{A}_{6} & =[700,800] ; \\
\mathrm{A}_{7} & =[800,900] ; \\
\mathrm{A}_{8} & =[900,1000] ; \\
\mathrm{A}_{9} & =[1000,1100] ; \\
\mathrm{A}_{10} & =[1100,1200] ; \\
\mathrm{A}_{11} & =[1200,1300] ; \\
\mathrm{A}_{12} & =[1300,1400] ; \\
\mathrm{A}_{13} & =[1400,1500] ; \\
\mathrm{A}_{14} & =[1500,1600] ; \\
\mathrm{A}_{15} & =[1600,1700] ;
\end{array}
$$

\section{Langkah 6, 7 dan 8.}

Untuk lebih memperjelas langkahlangkah 6, 7 dan 8, dapat dilihat pada Tabel 3 dan Tabel 4. 
Tabel 3. Fuzzy Sets

(Algoritma Novel)

\begin{tabular}{|c|c|c|}
\hline Year & $\begin{array}{c}\text { Historical } \\
\text { Data }\end{array}$ & $\begin{array}{c}\text { Fuzzy } \\
\text { Sets }\end{array}$ \\
\hline 2000 & 279,11 & A1 \\
\hline 2001 & 271,04 & A1 \\
\hline 2002 & 309,73 & A2 \\
\hline 2003 & 363,38 & A2 \\
\hline 2004 & 409,72 & A3 \\
\hline 2005 & 444,74 & A3 \\
\hline 2006 & 603,46 & A5 \\
\hline 2007 & 695,39 & A5 \\
\hline 2008 & 871,96 & A7 \\
\hline 2009 & 972,35 & A8 \\
\hline 2010 & 1224,53 & A11 \\
\hline 2011 & 1571,52 & A14 \\
\hline 2012 & 1668,98 & A15 \\
\hline 2013 & 1411,23 & A13 \\
\hline 2014 & 1266,4 & A11 \\
\hline 2015 & 1160,06 & A10 \\
\hline
\end{tabular}

Tabel 4. Hasil Prediksi Algoritma Novel

\begin{tabular}{|c|c|c|}
\hline Year & $\begin{array}{c}\text { Data } \\
\text { Historis }\end{array}$ & $\begin{array}{c}\text { Hasil } \\
\text { Prediksi }\end{array}$ \\
\hline 2000 & 279,11 & - \\
\hline 2001 & 271,04 & 250 \\
\hline 2002 & 309,73 & 350 \\
\hline 2003 & 363,38 & 350 \\
\hline 2004 & 409,72 & 450 \\
\hline 2005 & 444,74 & 450 \\
\hline 2006 & 603,46 & 625 \\
\hline 2007 & 695,39 & 650 \\
\hline 2008 & 871,96 & 875 \\
\hline 2009 & 972,35 & 950 \\
\hline 2010 & 1224,53 & 1250 \\
\hline 2011 & 1571,52 & 1550 \\
\hline 2012 & 1668,98 & 1650 \\
\hline 2013 & 1411,23 & 1450 \\
\hline 2014 & 1266,4 & 1250 \\
\hline 2015 & 1160,06 & 1150 \\
\hline
\end{tabular}

\section{Evaluasi Hasil Prediksi}

Dari hasil perhitungan pada Tabel 4, selanjutnya menghitung persentase eror/ kesalahan terhadap hasil peramalan yang telah dilakukan menggunakan metode Mean Absolute Percentage Error (MAPE). Sebagai tambahan, penulis juga telah melakukan perhitungan prediksi harga emas dengan data yang sama di atas, menggunakan Algoritma Fuzzy Time Series - Rantai Markov yang dikemukakan oleh Tsaur (2012) sebagai metode pembanding, yang hasilnya bisa dilihat pada Tabel 5 .

Tabel 5. Evaluasi Hasil Prediksi dengan MAPE

\begin{tabular}{|c|c|c|c|}
\hline Tahun & $\begin{array}{c}\text { Data } \\
\text { Historis }\end{array}$ & $\begin{array}{c}\text { Hasil } \\
\text { Prediksi } \\
\text { (Algoritma } \\
\text { Novel) }\end{array}$ & $\begin{array}{c}\text { Hasil } \\
\text { Prediksi } \\
\text { (Algoritma } \\
\text { Rhuey Chyn } \\
\text { Tsaur) }\end{array}$ \\
\hline 2000 & 279,11 & - & - \\
\hline 2001 & 271,04 & 250 & 326.07 \\
\hline 2002 & 309,73 & 350 & 320.69 \\
\hline 2003 & 363,38 & 350 & 346.49 \\
\hline 2004 & 409,72 & 450 & 441.69 \\
\hline 2005 & 444,74 & 450 & 414.86 \\
\hline 2006 & 603,46 & 625 & 632.37 \\
\hline 2007 & 695,39 & 650 & 720 \\
\hline 2008 & 871,96 & 875 & 920 \\
\hline 2009 & 972,35 & 950 & 1020 \\
\hline 2010 & 1224,53 & 1250 & 1220 \\
\hline 2011 & 1571,52 & 1550 & 1620 \\
\hline 2012 & 1668,98 & 1650 & 1554.35 \\
\hline 2013 & 1411,23 & 1450 & 1444.49 \\
\hline 2014 & 1266,4 & 1250 & 1220 \\
\hline 2015 & 1160,06 & 1150 & 1120 \\
\hline \multicolumn{2}{|c|}{ MAPE } & $\mathbf{0 . 0 3 8 5}$ & $\mathbf{0 . 0 5 4 4}$ \\
\hline \multicolumn{2}{|c|}{ Persentase (\%) } & $\mathbf{3 . 8 4 6 7}$ & $\mathbf{5 . 4 3 6 8}$ \\
\hline
\end{tabular}

Untuk lebih memperjelas hasil prediksi menggunakan Algoritma Novel, yang telah dibandingkan dengan 
Algoritma Rhuey Chyn Tsaur, dapat dilihat pada Gambar 1.

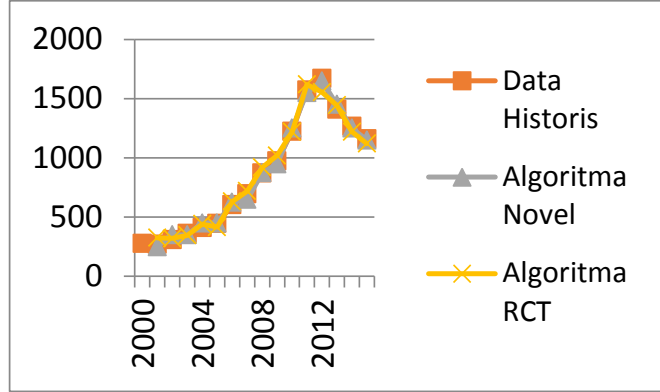

Gambar 1. Grafik Perbandingan Hasil Prediksi

\section{KESIMPULAN}

Dari hasil penelitian yang telah dilakukan, maka dapat ditarik kesimpulan hasil prediksi harga emas menggunakan Algoritma Novel, didapat hasil peramalan yang mendekati nilai aslinya dengan tingkat kesalahan yang kecil dengan nilai perhitungan kesalahan menggunakan metode MAPE sebesar $\mathbf{0 , 0 3 8 5}(3,85 \%)$, sedangkan hasil dari metode Algoritma Ruey Chyn Tsaur sebagai pembanding, memperoleh nilai selisih yang lebih besar dengan nilai perhitungan kesalahan menggunakan metode MAPE sebesar $\mathbf{0 , 0 5 4 4}(5,44 \%)$. Hal ini menunjukkan metode peramalan menggunakan Algoritma Novel mempunyai hasil prediksi/ peramalan yang lebih akurat dibandingkan dengan metode Algoritma Ruey Chyn Tsaur.

\section{SARAN}

Dari hasil penelitian ini, maka penulis dapat memberikan saran antara lain sebagai berikut :

1. Hasil pengujian tingkat akurasi Algoritma Novel sebagai Metode Prediksi inidiharapkan dapat dipergunakan oleh penulis berikutnya yang ingin melakukan penelitian serupa tentang prediksi/ peramalan.

2. Bagi penulis selanjutnya agar dapat membandingkan dua metode ini dengan metode peramalan yang lain untuk melihat tingkat keakuratan hasil peramalan antara metode-metode tersebut.

\section{DAFTAR PUSTAKA}

Apriliyah, Mahmudy WF dan Widodo AW.2008. Perkiraan Penjualan Beban Listrik Menggunakan Jaringan Syaraf Tiruan Resilent Backpropagation (RProp).Kursor, vol. 4, no. 2, pp. 41-47.

Berutu, SS., 2013. Peramalan Penjualan Dengan Metode Fuzzy Time Series Ruey Chyn Tsaur. Tesis. Universitas

Diponegoro,

Semarang.

Chen S. M, 2002. Forecasting Enrollments Based on High-order Fuzzy Time Series. Cybernetics and Systems : An International Journal 33 1-16.

Duru, O., Yoshida S., 2009. Comparative Analysis of Fuzzy 
Time Series and Forecasting : an Empirical Study of Forecasting Dry Bulk Shipping Index.

Jasim, Haneen Talal, Abdul G.J. Salim dan K. I. Ibraheem. 2012. A Novel Algorthm to Forecast Enrollment Based On Fuzzy Time Series. Applications and Applied Mathematics : An International Journal, Vol. 7, Issue 1 (June 2012), pp 385-397.

Kusumadewi, Sri. 2003. Artificial Intelegent (Teknik dan Aplikasinya). Graha Ilmu, Yogyakarta.

Lee L. W, Wang L. H, Chen S. M, Leu Y. H. 2006.Handling Forecasting Problems based on Two Factors High-order Fuzzy Time Series. IEEE Transactions on Fuzzy Systems 14(3) 468-477.

Puspitasari, E., Linawati,L., Parhusip, H.A., 2012. Simulasi Peramalan IndeksHarga Saham Gabungan (IHSG) Dengan Fuzzy Time Series Using Precentage Change. Jurnal.

Song, Q dan Chissom B.S., 1993. Forecasting enrollment with fuzzy time series - Part I, Fuzzy Sets and Systems, vol.54, no.1, pp. 1-9.

Stevenson, Meredith and John E. Porter. 2009. Fuzzy Time Series Forecasting Using Percentage Change as the Universe of Discourse. World Academy of Science, Engineering and Technology 55.

Supriyono.2007. Analisis Perbandingan Logika Fuzzy Dengan Regresi
Berganda Sebagai Alat Peramalan. Seminar Nasional III SDM Teknologi Nuklir,Yogyakarta, ISSN 19780176.

Tsai C. C, Wu S. J. 1999. A Study for Second Order Modeling of Fuzzy Time Series.IEEE international fuzzy systems conference proceedings II, August 22-25, Seoul, Korea 719-725.

Tsaur, R. C. 2012. A Fuzzy Time Series Markov Chain Model With an Application To Forecast The Exchange Rate Between Taiwan and US Dollar, ICIC International, vol.8, no.7, pp.4931-4942. 